\title{
Spatiotemporal Variations of Land Use and Landscape Ecological Risk in a Resource-Based City, from Rapid Development to Recession
}

\author{
Shiyuan Zhou', Jiang Chang ${ }^{1 *}$, Tinghao Hu${ }^{1}$, Pingjia Luo², Hongxuan Zhou² \\ ${ }^{1}$ School of Mechanics and Civil Engineering, China University of Mining and Technology, Xuzhou, P.R. China \\ ${ }^{2}$ School of Architecture and Design, China University of Mining and Technology, Xuzhou, P.R. China
}

Received: 27 October 2018

Accepted: 12 January 2019

\begin{abstract}
The ecological environment of resource-based cities is threatened by multiple ecological risks. The main objective of this study is to investigate the dynamics of land use and landscape ecological risk in resource-based cities. Huaibei, a typical resource-based city in China, was taken as a case study. By using the Markov model and landscape metrics, this study first analysed the land use changes in 1989, 2002 and 2016. Then an assessment model was developed to examine the ecological risk caused by the land use changes. Additionally, a spatial autocorrelation analysis was adopted to reflect the spatial heterogeneity of the landscape ecological risk. The results showed that urbanization has a greater impact on land use than the mining activity in Huaibei. The level of landscape ecological risk showed a tendency to initially increase and then decrease. In 1989 and 2002, the extremely high and high-risk regions were concentrated in the northern mining area, but these regions were reduced and scattered throughout the northern and middle areas of Huaibei in 2016. The area of medium-risk regions continuously increased throughout the study period. The spatial autocorrelation of the landscape ecological risk was positive and was weakened in 2016. The results suggest that the pattern of land use and the landscape ecological risk in resource-based cities showed an obvious spatiotemporal variation. Understanding the phase characteristics is necessary for ecological restoration.
\end{abstract}

Keywords: ecological risk assessment, resource-based cities, land use change, ecological restoration

\section{Introduction}

A healthy ecosystem provides various ecological services for human beings and it is the foundation for

*e-mail: changjang102@163.com the sustainable development of human society. However, human activities and natural disasters inevitably interfere with the evolution of an ecosystem at different scales [1-2]. Ecological risk refers to the possibility that the ecosystem structure and function will be degenerated under external pressure [3]. Ecological risk assessment (ERA) is an effective method for quantifying 
the potential impacts and the cumulative effects of risk sources [4]. Landscape ecological risk assessment (LERA) which is an important branch of ERA focuses on the ecological risk caused by land use changes [5]. It aims to reveal the effect of landscape pattern change on the ecological process [6-7]. In recent years, LERA has been used to analyse the response of the regional ecological environment to human disturbance. It has been a powerful tool for balancing and managing ecological risk and could provide a reference for policy makers and land use planners.

ERA has been proposed with the development and subdivision of environmental impact assessments. At first, it was popular in ecological toxicology and was useful for explaining the formation and diffusion of chemical pollution and the response of the regional ecological system [8]. In the 1990s, the research objective, content and method of ERA were greatly extended [9-10]. Some scholars began to pay attention to the ecological risk caused by land use changes. Compared with the traditional ERA, LERA provided a special focus on spatial heterogeneity. So far, research on various landscapes, such as forests [11], coastal areas [4], arid desert areas [12], national parks [13], cities [14-15] and mining areas [16], have been performed. The key step of a LERA is to establish the ecological risk index (ERI). There are two methods that are currently widely used. The first is based on the model of 'stressor-receptor-response' [17] and a hazard analysis chain of ecological risks. This method is usually used to analyse the ecological effect of specific stressors or disturbances. The second method regards the ecological effect of landscape mosaic deviating from the optimal pattern as a risk source [7]. The entire ecosystem, rather than the specific ecological components, is considered to be the receptor. In the second method, the ERI is determined by ecological risk probability and landscape ecological loss index. In some studies, landscape ecological loss index was calculated by the analytic hierarchy process (AHP) or the Delphi method. However, most studies used landscape disturbance index and landscape fragility index to calculate the landscape ecological loss index [4]. The landscape disturbance index was calculated by landscape metrics. The landscape fragility index was usually obtained by artificial assignment or the normalization method, while some studies calculated it by using the index, which could quantitatively describe the ecological characteristics of the risk receptor, such as vegetation index, wetness index and topographic index [18]. Either way, both the selection of the assessment method and the construction of ecological risk index should be in accordance with the research purpose and the ecological characteristics of the research object.

Resource-based cities are those cities in which the exploits and processes local natural resources is the dominant industry. Compared with other types of cities, resource-based cities are characterized by the life cycle [19]. The development could be divided into four phases: initial period, rapid development period, mature period and recession period. Generally, the city will be deemed to be in the recession period when the mining activity lasts for more than 50 years or the remaining reserves can be mined within 10 years [20]. With the profound change of land use, the ecological environment will be seriously damaged, and the risk grade will sharply rise when a resource-based city is in the recession period. Therefore, the resource-based cities have become a hot issue for the research of restoration ecology [21-22]. Many experts called for a mechanism by which environmental monitoring, risk assessments and policy decision making should be developed [11]. Based on this background, some studies paid attention to the ERA for resource-based cities [23]. At first, most of the previous works focused on the ecological risks that were caused by chemical pollution, such as threats from heavy metal and acid mine drainage. However, there is a very limited number of papers that have assessed the landscape ecological risk in resource-based cities. Most of the previous studies only assessed the landscape ecological risk in a single period, which led to confusion about the spatiotemporal evolution of ecological risk. In Addition, an inadequate analysis of the land use changes resulted in difficulty for most studies to explain the evolutionary mechanism of landscape ecological risks in different grades.

In resource-based cities, the mining industry drives the land use changes directly or indirectly. Taking Huaibei as an example, this study has shown the phase characteristics of land use and landscape ecological risk from the rapid developed period to the recession period. The land use conversion was demonstrated by the Markov model and landscape metrics. On this basis, an ERI was established to evaluate the landscape ecological risk of Huaibei in different periods. Moreover, the conversion of different risk grades was calculated. At last, the spatial correlation for the landscape ecological risk in different years was calculated.

\section{Study Area and Data}

\section{Study Area}

Huaibei $\left(33^{\circ} 16^{\prime}\right.$ to $34^{\circ} 14^{\prime} \mathrm{N}, 116^{\circ} 23^{\prime}$ to $\left.117^{\circ} 02^{\prime} \mathrm{E}\right)$ lies in northern Anhui Province in China. It consists of four administrative parts, namely Duji, Xiangshan, and Lieshan Districts and Suixi County, together with 11 towns. The total area of Huaibei is $2741 \mathrm{~km}^{2}$, in which plains account for $85.3 \%$ and hills account for only $14.7 \%$ (Fig. 1). The plain grows in the altitude ranging from $22.5 \mathrm{~m}$ to $37 \mathrm{~m}$. The average altitude of the hilly area is above $200 \mathrm{~m}$. Huaibei belongs to the subhumid warm temperate continental monsoon climate. In the plain area, the level of shallow groundwater is relatively high, so it easily forms waterlogged subsidence basins after mining [24]. 


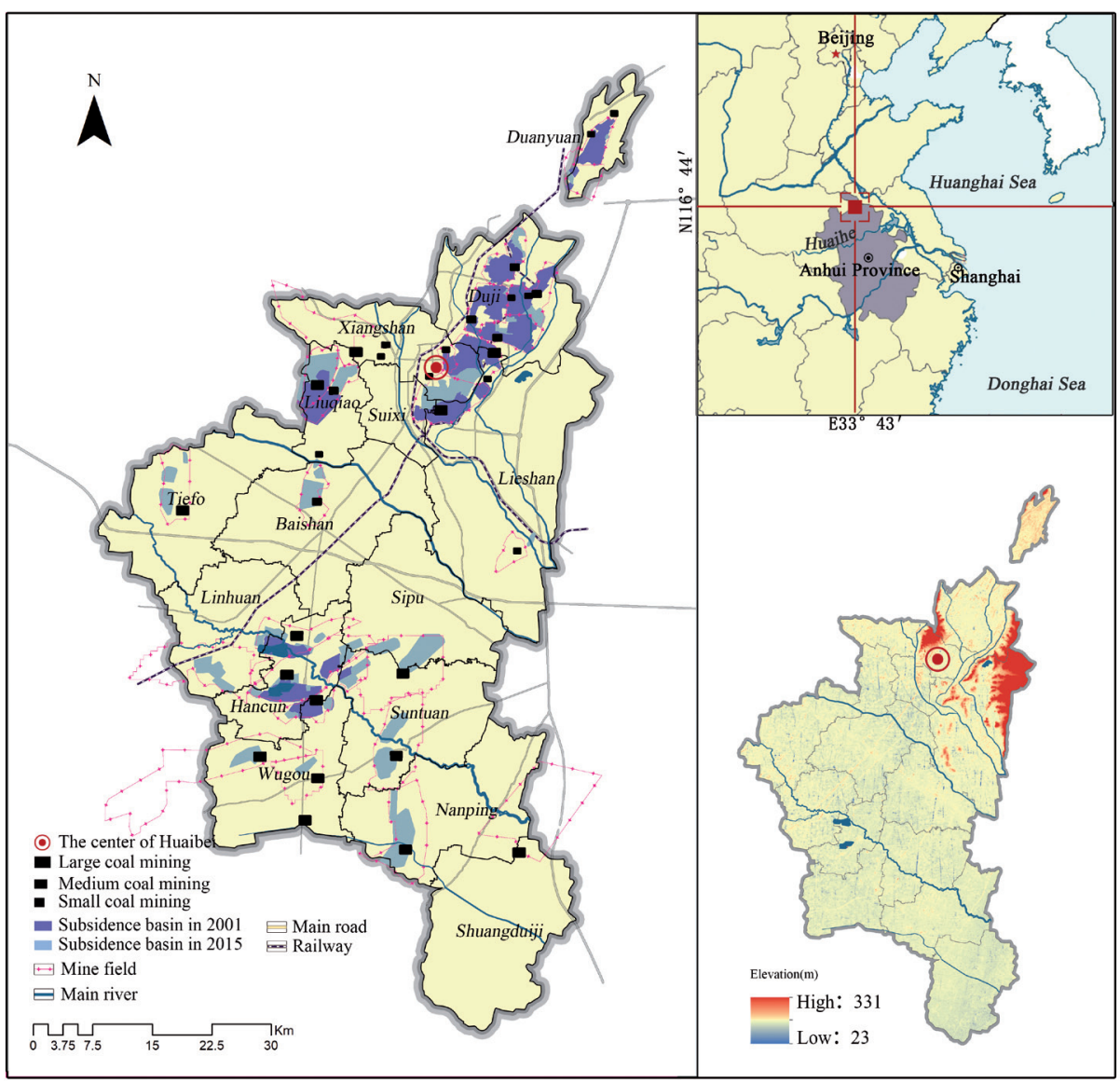

Fig. 1. Location of Huaibei in China and the distribution of coal mines.

Huaibei is an important part of the Lianghuai energy base, which is nearest to the Yangtze River Delta region. In 1960, Huaibei was established because of the exploitation of coal. By the end of 2016, the cumulative production of coal was nearly 1 billion tons. It once had an important impact on the energy supply for eastern China. In the 1980s, Huaibei was in a rapid development period. The late 1990 s to the early $21^{\text {st }}$ century was the mature period of Huaibei's mining industry. Later, due to the decline of coal reserves, Huaibei stepped into the recession period and it was identified as a resourceexhausted city by China's State Council in 2009. After nearly 60 years of mining, there are still 29 coal mines, most of which are close to closure. The long-term mining of coal posed a serious threat to ecological security and restricted the sustainable development of the city. Influenced by deep coal mining, a large amount of subsidence basins emerged, which has become the most prominent problem of ecological restoration in the mining areas. By 2015 , a total of $166.8 \mathrm{~km}^{2}$ of land sank and the subsidence area still increased by $1.1 \mathrm{~km}^{2}$ per year.

Since the $21^{\text {st }}$ century, the urbanization rate of Huaibei increased from $37.9 \%$ in 2001 to $62.1 \%$ in 2016. The rapid urbanization caused an obvious change in the land use [25], especially the growth of construction land which resulted in higher landscape fragmentation [26]. Currently, the impact of urbanization on the landscape pattern has become stronger.

\section{Data Source}

This study was conducted mainly based on the following sources: the administrative district map, the land use maps, the maps of the mining area and statistical data on social and economic development. The land use maps were made from Landsat TM and ETM images in 1989 (the rapid development period), 2002 (the mature period) and 2016 (the recession period), which were obtained from USGS. Every image is a summer scene that was acquired from June to August. Image data preprocessing and interpretation was performed by ERDAS IMAGINE2014 and Arc GIS 10.2 [27]. According to previous studies and the Chinese national land use classification criteria, the landscape of Huaibei was classified into cultivated land, forest, grass land, water area, construction land and unused land (Table 1 and Fig. 2). The maps of the mining area were used to identify the risk source and to optimize the land use classification result, including the distribution maps of coal mines and subsidence basins in different years. All of these data and maps above were derived from the Huaibei land bureau. The 
Table 1. Classification of land use of Huaibei.

\begin{tabular}{|c|c|c|}
\hline Code & Land Use Type & Details \\
\hline 1 & Cultivated land & Irrigated land, Paddy field. \\
\hline 2 & Forest & $\begin{array}{c}\text { Wildwood mainly in hilly areas of the prohibition of development, plantation mainly on the plain, } \\
\text { shrubs. }\end{array}$ \\
\hline 3 & Grass land & Natural grassland in hilly area, cultivated grassland for pasture. \\
\hline 4 & Water area & River, lake, reservoir, the waterlogged subsidence basin. \\
\hline 5 & Construction land & Build-up area of urban and town, rural, industrial and mining areas. \\
\hline 6 & Unused land & Abandoned mine land, sand, bare land. \\
\hline
\end{tabular}

DEM dataset $(30 \times 30 \mathrm{~m})$ came from the 'Geospatial data cloud' provided by the Chinese Academy of Sciences.

\section{Sampling Method}

Dividing the landscape ecological risk unit is necessary for calculating the ERI and the spatial statistical analysis. According to the previous studies, the variation coefficient model was used to decide the size of the sampling unit [28]. After comparing 10 sizes of sampling units, the results show that $1.5 \times 1.5 \mathrm{~km}$ is the optimal grid size. Therefore, the study area was divided into 1339 risk units using the equidistance sampling method (Fig. 3). It is necessary to calculate the ERI of each sampling unit to quantitatively describe the spatial distribution and the changes in the landscape ecological risk. Meanwhile, the centre points of sampling units are the basis of spatial interpolation.

\section{Methods}

\section{Land Use Dynamic Change}

In this study, the phase characteristics of land use were reflected by the Markov transition matrix [29]. As a densely populated district, the land use intensity of Huaibei is very high. Therefore, the Markov transition matrix largely reflects the disturbance manner and intensity of human activities at the regional scale. This study analyses the land use changes of Huaibei from 1989 to 2016. The conversion of different land use types was analysed by the intersect tool of Arc GIS 10.2:

$$
S_{i j}=\left\{\begin{array}{cccc}
S_{11}, & S_{12}, & \ldots & S_{1 n} \\
S_{21}, & S_{22}, & \ldots & S_{2 n} \\
\ldots & & & \\
S_{m 1} & S_{m 2} & \ldots & S_{m n}
\end{array}\right\}
$$

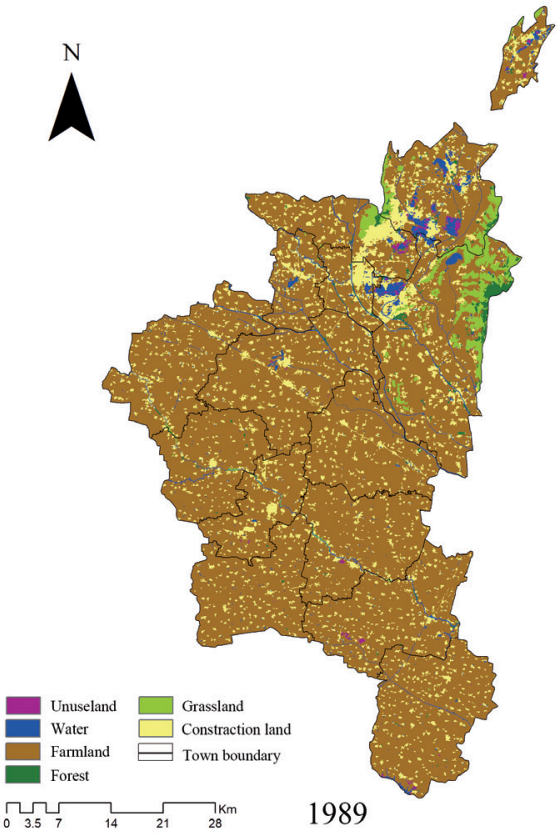

Fig. 2. Land use distribution in Huaibei from 1989 to 2016.

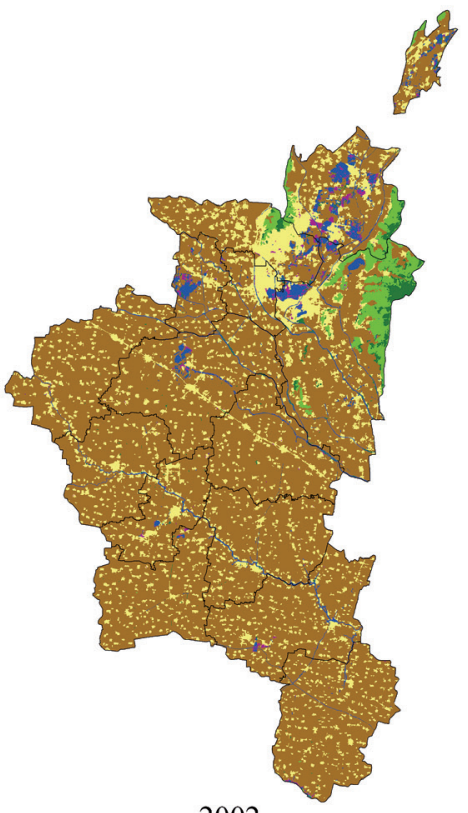

2002

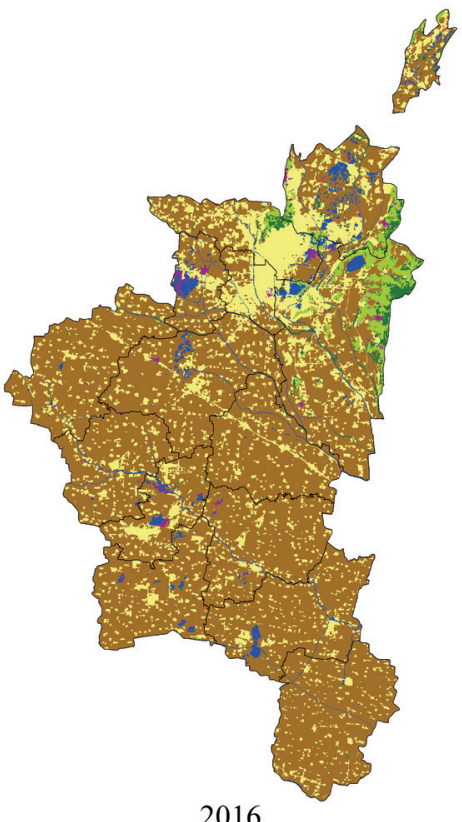

2016 


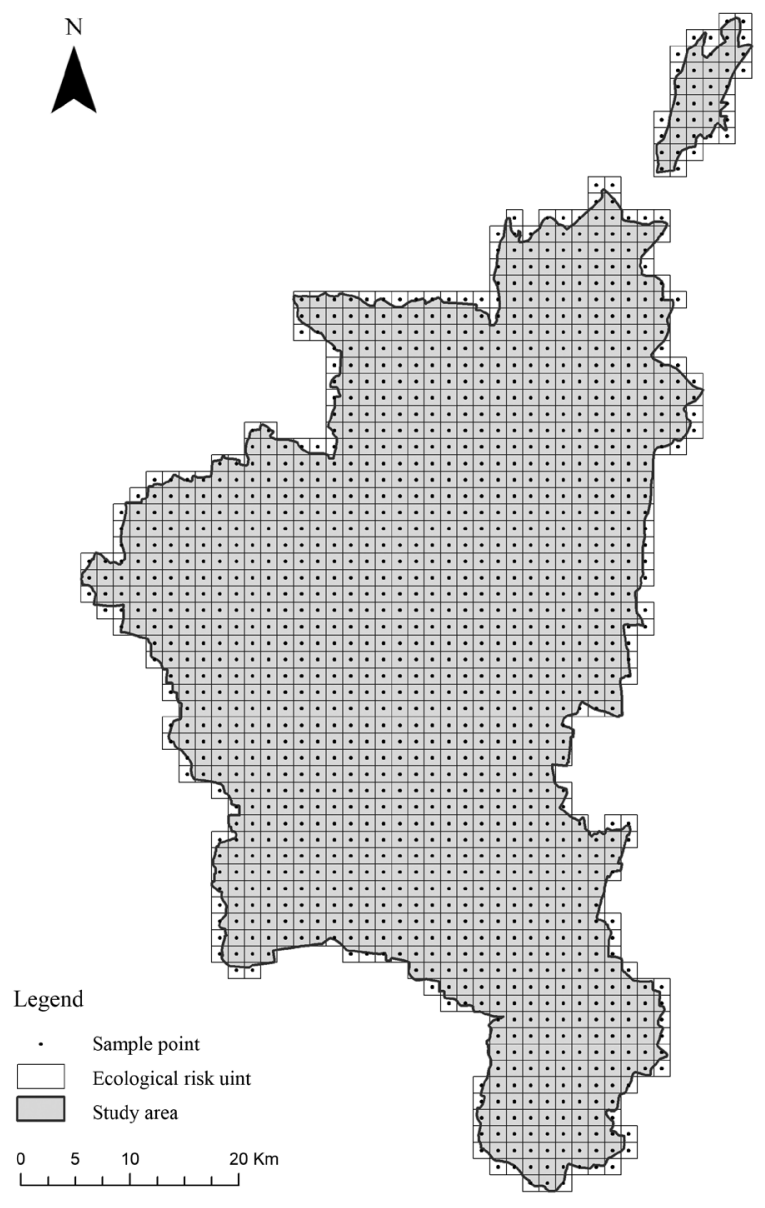

Fig. 3. Division of the landscape ecological risk unit.

...where $S_{i j}$ is the changing area from land use $i$ to $j$ between two time points, and $m$ and $n$ are the number of land use types.

\section{Landscape Ecological Risk Assessment Model}

Landscape Ecological Risk Index (ERI)

The level of landscape ecological risk is determined by the integrity of landscape structure and the loss degree of the ecosystem. The ERI was established to quantify the risk level of each unit. It was constructed by combining the land use structure of each risk unit and the landscape ecological loss degree of each land use type, which was calculated by the landscape disturbance index $\left(E_{i}\right)$ and the landscape fragility index $\left(F_{i}\right)$. The assessment formula is expressed as Eq. 2 [12]:

$$
E R I=\sum_{i=1}^{n} \frac{A_{k i}}{A_{k}}\left(E_{i} \times F_{i}\right)
$$

...where $A_{k i}$ is the area of the $i t h$ land use in the $k$ th risk unit, $A_{k}$ is the total area of the $k t h$ risk unit, and $n$ is the number of land use types.

\section{Landscape Disturbance Index (E)}

Human activities and natural disasters changed the land use structure and the landscape ecological process, such as mining, urbanization, farming, flood or drought, etc. Therefore, comparing the landscape metrics in different periods would effectively reflect the manner and process of disturbance [30]. Considering the land use characteristics of Huaibei, class landscape metrics with different ecological significances were selected to establish the landscape disturbance index (Table 2). The landscape disturbance index could quantify the resistance of landscape pattern to external disturbances. Generally, $E_{i}$ was built by using the fragmentation index $\left(C_{i}\right)$, segmentation index $\left(S_{i}\right)$ and dominant index

Table 2. Indices of landscape disturbance.

\begin{tabular}{|c|c|c|}
\hline Index & Equation & Expression \\
\hline$C_{i}$ & $C_{i}=n_{i} / A_{i}$ & $n_{i}$ is the patch number of landscape $i ; A_{i}$ is the total area of landscape $i$. \\
\hline$S_{i}$ & $S_{i}=A \times \sqrt{n_{i} / A} / 2 A_{i}$ & $A$ is the total area of landscape. \\
\hline$D o_{i}$ & $D o_{i}=\left(Q_{i}+M_{i}\right) / 4+L_{i} / 2$ & $\begin{array}{l}Q_{i} \text { is the number of risk units with the patch } i \text { divided by the total } \\
\text { number of risk units; } M_{i} \text { is the number of patch of landscape } i \text { divided } \\
\text { by the total number of patches in the risk units; } L_{i} \text { is the area of land- } \\
\text { scape } i \text { divided by total area of risk units. }\end{array}$ \\
\hline$R P_{i}$ & $\begin{array}{c}R P_{i}=1 / \text { PAFRAC } \\
\text { PAFRAC }=\frac{\left[n_{i} \sum_{j=1}^{n}\left(\ln p_{i j} \times \ln a_{i j}\right)\right]-\left[\left(\sum_{j=1}^{n} \ln p_{i j}\right) \times\left(\sum_{j=1}^{n} \ln a_{i j}\right)\right.}{\left(a_{i} \sum_{j=1}^{n} p_{i j}^{2}\right)-\left(\sum_{j=1}^{n} \ln p_{i j}\right)}\end{array}$ & $\begin{array}{c}a_{i j} \text { is the area of patch } i j \\
P_{i j} \text { equals perimeter of patch } i j\end{array}$ \\
\hline$N_{i}$ & $N_{i}=\left(e_{i}-\min e_{i}\right) /\left(\max e_{i}-\min e_{i}\right)$ & $\begin{array}{c}e_{i} \text { equals perimeter of landscape } i ; \text { mine }_{i} \text { equals minimum perimeter of } \\
\text { landscape } i ; \max e_{i} \text { equals maximum perimeter of landscape } i .\end{array}$ \\
\hline$E_{i}$ & $E_{i}=a C_{i}+b S_{i}+c D o_{i}+d P R_{i}+e N_{i}$ & $\begin{array}{l}a, b, c, d, e \text { represent the weights of } C_{i}, S_{i}, D o_{i}, R P_{i}, N_{i} a+b+c+d \\
+e=1\end{array}$ \\
\hline
\end{tabular}


$\left(D o_{i}\right)$ [31]. The $C_{i}$ is an important index for describing landscape heterogeneity. The extent of fragmentation has an important impact on maintaining the ecological function of habitats. The $S_{i}$ stands for the separation degree of $i t h$ land use. The higher $S_{i}$ means the greater conversion probability between different landscape types. The $D o_{i}$ shows the dominance of $i t h$ land use in the whole area, which also reflects the deviation between landscape diversity and maximum diversity. These class landscape metrics can measure the stability of spatial structure of a certain land use type in response to external disturbances. However, the disturbance effects on the stability of patch shape of a land use type cannot be fully reflected in these indices. By referring to the latest studies, this study adds the reciprocal of perimeter-area fractal dimension index $\left(R P_{i}\right)$ [32-33] and the normalized landscape shape index $\left(N_{i}\right)$ [12] to the formula. PAFRAC, which has a range from 1 to 2 , describes the path shape complexity and stability at the class level. The value of PAFRAC approaches 1, which indicates that when the patch presents a simpler shape, the disturbance it suffered will be stronger. The $N_{i}$ is the normalized version of the landscape shape index at the class level. The high $N_{i}$ means that the interior area of the landscape unit is relatively small and the edge area is large. The landscape ecological process is more easily influenced by external disturbances.

Disturbance is dynamic, and its influence on the landscape pattern shows an obvious temporal variation. Therefore, the weights of the landscape metrics for different periods should be modified. In this study, the entropy weight method is employed for allotting weights to the landscape metrics of different periods. This method is regarded as a relatively objective and effective method for obtaining the contribution of each index to the landscape disturbance indices [34-35]. The weights of the landscape metrics in 1989 are $a=0.219, b=0.244, c=0.260, d=0.114$, and $e=0.164$. The weights in 2002 are $a=0.232, b=0.243$, $c=0.294, d=0.095$, and $e=0.136$. The weights in 2016 are $a=0.204, b=0.250, c=0.287, d=0.095$, and $e=0.164$.

\section{Landscape Fragility Index $(F)$}

Different landscape types stand for different ecosystems, which have different abilities to maintain the stability of the ecological process. $F_{i}$ is the sensitivity of $i t h$ land use to external disturbances [12]. The higher $F_{i}$ means that the landscape stability is lower and the ecosystem is more vulnerable. The results of previous studies generally proved that the landscape fragility of unused land, water area and cultivated land were very high [4]. These landscape types easily lost the original landscape structure and the ecological function under external disturbances. The landscape fragility of grassland and forest is relatively low [35]. It is usually believed that the construction land was the most stable landscape [18]. When compared with other study areas, the landscape fragility of the construction land in resource-based cities was relatively higher [36]. On the one hand, after the closure of coal mines, the economic recession and the loss of the employment population resulted in a large amount of construction land being abandoned and changed to unused land. On the other hand, many villages disappeared because of mining subsidence. By 2016, there was still more than $87 \mathrm{~km}^{2}$ of construction land located in the coal fields (excepting the closed coal mines), most of which was rural settlement. With the further exploitation of coal, many villages had to move. Therefore, the AHP method was used to calculate the $F_{i}$ of each landscape by using IDRISI Selva17.2 [37]. The final $F_{i}$ values for unused land, water area, cultivated land, grass land, forest and construction land were $0.283,0.229,0.142,0.123,0.115$ and 0.108 , respectively. The conformance index was $0.0288(<0.05)$.

\section{Spatial Statistical Analysis}

\section{Semivariance Analysis}

As a spatial variable, the spatial variability of the landscape ecological risk is structural and random. The semivariance function (Eq. 5), which is an important method of geostatistics, is very useful for measuring the continuity of the adjacent space variables [38]. Therefore, it was performed to simulate the gradient change of the landscape ecological risk, especially for local optimization spatial interpolation, namely Kriging interpolation. The experimental semivariance function was calculated by using the $\mathrm{GS}^{+} 7.0$ tool and then fitted by an appropriate theoretical model determined mainly by the determination coefficient $\left(R^{2}\right)$ and the residual sum of squares (RSS) [39]. Then the results would provide semivariance values for any $h$ that are necessary for Kriging interpolation. The landscape ecological risk maps in 1989, 2002 and 2016 were created with the help of geostatistics analysist tools of Arc GIS 10.2.

$$
\gamma(h)=\frac{1}{2 N(h)} \sum_{i=1}^{N(h)}\left[Z\left(x_{i}\right)-Z\left(x_{i}+h\right)\right]^{2}
$$

...where $\gamma(h)$ is the experimental semivariance value at the distance interval $h$, which describes the degree of autocorrelation that is present; $N(h)$ is the number of risk units at lag distance $h ; Z\left(x_{i}\right)$ and $Z\left(x_{i}+h\right)$ are the sample values at location $x_{i}$ and $x_{i}+h(i=1,2, \ldots, N(h))$.

\section{Spatial Autocorrelation Analysis}

Spatial autocorrelation analysis is used to describe the correlation of the ERI in adjacent locations. It is helpful to observe the spatial heterogeneity of landscape ecological risk [39]. It includes global spatial autocorrelation and local spatial autocorrelation, which were calculated by Moran's I and LISA, using Geo 


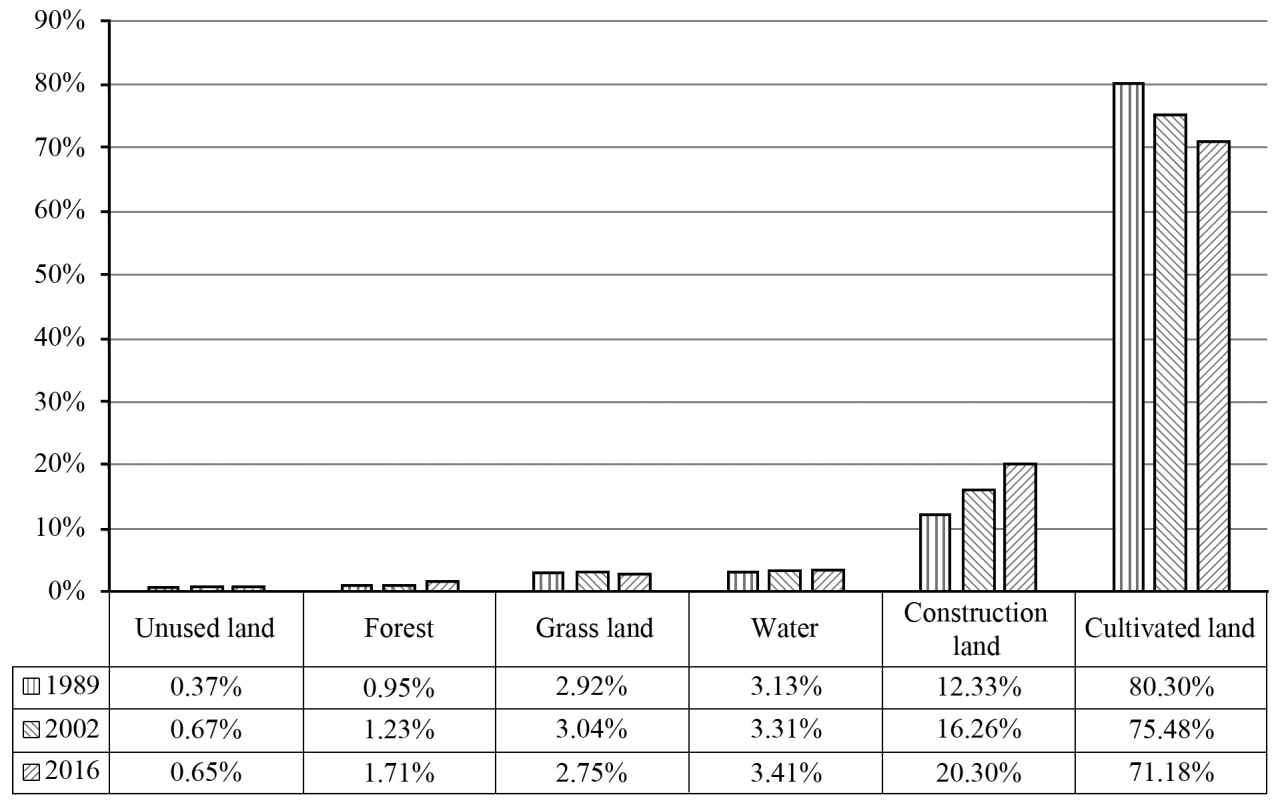

Fig. 4. Land use proportions of Huaibei in 1989, 2002 and 2016.

Da 1.12 [40]. The value of Moran's I varied between -1 to 1 . Positive, negative or near-zero indicate that the distribution of risk units with similar values has a clustering, dispersion or random pattern, respectively [41]. In this case, Moran's I for the ERI was calculated in 6 distance classes from 1989 to 2016 in order to show the change trend of the landscape ecological risk spatial clustering characteristics.

LISA could measure the local spatial association of the landscape ecological risk. According to the $z$ score significance, the clustering pattern of the landscape ecological risk was categorized into five types: $\mathrm{H}-\mathrm{H}$ (hot-spot), H-L, L-H, L-L (cold-spot) and not significant. $\mathrm{H}-\mathrm{H}$ signifies that the agglomeration consisted of higher ecological risk units, whereas L-L represents the contrary. The neighbouring risk units interact with each other and the change trend of risk is consistent. In the areas covered by $\mathrm{H}-\mathrm{H}$ clusters, the probability of the risk rising is higher. Comparing the change of $\mathrm{H}-\mathrm{H}$ clusters is helpful to reflect the spread direction of ecological risk and to identify the key areas for ecological restoration. This could provide a warning about the safety of an important ecological patch by comparing the change of the L-L clusters. H-L indicates that the statistically significant regions in high risk are surrounded by low risk regions. $\mathrm{L}-\mathrm{H}$ refers to the contrary. Both $\mathrm{H}-\mathrm{L}$ and $\mathrm{L}-\mathrm{H}$ indicate that there is a great difference among the neighbouring risk units in the ERI. Not significant signifies that the ERI is randomly distributed, and there is no obvious relationship among neighbouring risk units. As a result, the local spatial cluster maps of the landscape ecological risk in Huaibei were generated.

\section{Results}

\section{Land Use Conversion Analysis}

The excessive exploitation of land is an important cause of rising ecological risk. Therefore, the land use composition and landscape pattern in different periods were analysed first. Land use maps in 1989, 2002 and 2016 are shown in Fig. 2. The proportions of different land use types in three years are shown in Fig. 4. By using the Markov model, the land use transition matrices of Huaibei were generated, namely Tables 3 and 4.

Table 3. Land use transition matrix of Huaibei from 1989 to $2002\left(\mathrm{~km}^{2}\right)$.

\begin{tabular}{|c|c|c|c|c|c|c|}
\hline $1989 / 2002$ & Water area & Cultivated Land & Forest & Grass Land & Unused Land & Construction Land \\
\hline Water area & 50.89 & 20.07 & 1.18 & 0.29 & 4.45 & 8.91 \\
\hline Cultivated land & 26.16 & 2038.10 & 6.33 & 14.03 & 7.51 & 109.36 \\
\hline Forest & 0.63 & 2.37 & 18.63 & 2.81 & 0.12 & 1.58 \\
\hline Grass land & 1.52 & 3.03 & 6.93 & 64.20 & 0.10 & 4.16 \\
\hline Unused land & 1.89 & 2.94 & 0.19 & 1.23 & 1.20 & 2.76 \\
\hline Construction land & 9.71 & 2.80 & 0.43 & 0.83 & 5.10 & 319.15 \\
\hline
\end{tabular}


Table 4. Land use transition matrix of Huaibei from 2002 to $2016\left(\mathrm{~km}^{2}\right)$.

\begin{tabular}{|c|c|c|c|c|c|c|}
\hline $2002 / 2016$ & Water area & Cultivated Land & Forest & Grass Land & Unused Land & Construction Land \\
\hline Water area & 55.35 & 26.89 & 0.38 & 0.17 & 1.59 & 6.44 \\
\hline Cultivated land & 25.23 & 1900.70 & 10.51 & 5.00 & 7.69 & 120.18 \\
\hline Forest & 0.21 & 3.79 & 27.23 & 1.48 & 0.50 & 0.48 \\
\hline Grass land & 0.10 & 7.02 & 4.76 & 67.22 & 2.17 & 2.11 \\
\hline Unused land & 3.62 & 7.10 & 2.58 & 0.95 & 0.89 & 3.34 \\
\hline Construction land & 8.91 & 6.03 & 1.35 & 0.66 & 4.97 & 424 \\
\hline
\end{tabular}

Except for cultivated land, the other land use types increased differently during 1989 to 2002 (Fig. 4). Cultivated land decreased the most, by $132.18 \mathrm{~km}^{2}$. While construction land (which increased by $107.89 \mathrm{~km}^{2}$ ) was the fastest growing land use type between 1989 and 2002. Unused land, forest, water area and grassland increased by $8.29 \mathrm{~km}^{2}, 7.55 \mathrm{~km}^{2}$, $5.02 \mathrm{~km}^{2}$ and $3.44 \mathrm{~km}^{2}$, respectively. Table 3 showed that $109.36 \mathrm{~km}^{2}$ of cultivated land changed into construction land, which was the largest change from 1989 to 2002. The mutual conversions between cultivated land and water area were also prominent. By comparing the land use maps and the mining subsidence maps, it could be found that under the influence of mining activity, $9.71 \mathrm{~km}^{2}$ of construction land sank and changed into water area over 13 years. While $8.91 \mathrm{~km}^{2}$ of water area changed into construction land, especially around the central city.

The trend of land use changes became more complicated during 2002 to 2016. Cultivated land, unused land and grassland decreased in the 14 years. However, construction land, water area and forest still kept increasing. In the aspect of land use composition, cultivated land decreased by $117.79 \mathrm{~km}^{2}$, with a proportion of $71.18 \%$ in 2016. At the same time, construction land increased by $110.64 \mathrm{~km}^{2}$, with a proportion of $20.3 \%$ in 2016 . The proportions of water area and forest increased to $3.41 \%$ and $1.71 \%$. Grass land and unused land decreased to $2.75 \%$ and $0.67 \%$, respectively. As Table 4 shows, $120.18 \mathrm{~km}^{2}$ of cultivated land changed into construction land, which represents $90.67 \%$ of new construction land between 2002 and 2016. The transition area between water area and cultivated land were also notable for $26.89 \mathrm{~km}^{2}$ and $25.23 \mathrm{~km}^{2}$, respectively. Over 14 years, many mines were closed but there was still $8.91 \mathrm{~km}^{2}$ of construction land that had sunk and changed into water area, because the process of mining subsidence was very slow. From 2002 to $2016,6.44 \mathrm{~km}^{2}$ of water area changed into construction land, which was less than that from 1989 to 2002 .

In the whole period, only cultivated land constantly decreased, and it was the main source of the increased construction land and water area. During 1989 to 2016, a total of $229.54 \mathrm{~km}^{2}$ cultivated land was converted into construction land, which took up $69.14 \%$ of the loss area of cultivated land from 1989 to 2002, and $71 \%$ from 2002 to 2016 . The opposite change occurred in construction land, which in 2016 was 1.65 times larger than that of 1989 . These changes indicated that urbanization was the primary driving force for the land use changes in Huaibei. Mining activity had an obvious impact on cultivated land, construction land, water area and unused land. During 27 years, a total of $51.39 \mathrm{~km}^{2}$ of cultivated land changed into water area, of which $38.47 \mathrm{~km}^{2}$ was caused by mining subsidence. A total of $40.8 \mathrm{~km}^{2}$ of construction land changed into other land use types, mostly occurring in the mining areas. As the ecological restoration in the mining areas, $13.08 \mathrm{~km}^{2}$ of waterlogged subsidence basin was reclaimed. Otherwise, unused land, which has an obvious characteristic of the life cycle, increased by $81.25 \%$ from 1989 to 2002 but then decreased by $3.67 \%$ from 2002 to 2016 . It kept pace with the development of the mining industry.

\section{Spatial Distribution Characteristics of Landscape Ecological Risk}

\section{Dynamics of Landscape Metrics}

The landscape metrics at class level are the essential components of LERA and they were used to measure the spatial pattern changes of each land use type in different periods (Table 5). In Huaibei, cultivated land and construction land are the main types of land use. From 1989 to 2016, the $C$ and $S$ of cultivated land remained the minimum, but presented a trend of accelerated increase. By contrast, the dominance of cultivated land was gradually decreasing. The minimum of PAFRAC and the maximum of $N$ occurred in 2002, which indicated that the stabilization of cultivated land patch was the worst when mining activity was in the mature period. With the expansion of the central city and villages, the $C$ and $S$ of construction land constantly decreased, but the Do gradually increased across the whole period. This is mainly because the growth of the central city occurred in an aggregation way. The patch of construction land was more unstable with a lower PAFRAC and a higher N. From 1989 to 2016, the $C$ and $S$ of unused land were the highest. The values of $C, S$, $D o$ and $N$ of unused land increased in 1989 to 2002, but dropped in 2002 to 2016, which indicated that the 
Table 5. Landscape metrics at class level in Huaibei from 1989 to 2016.

\begin{tabular}{|c|c|c|c|c|c|c|}
\hline Year & Type & $C_{i}$ & $S_{i}$ & $D o_{i}$ & $P A F R A C_{i}$ & $N_{i}$ \\
\hline \multirow{6}{*}{1989} & Water area & 0.0557 & 0.6672 & 0.1625 & 1.6288 & 0.1215 \\
\hline & Cultivated land & 0.0014 & 0.0209 & 0.6223 & 1.4083 & 0.0622 \\
\hline & Forest & 0.0624 & 1.2788 & 0.0639 & 1.3634 & 0.1169 \\
\hline & Grassland & 0.0230 & 0.4442 & 0.1214 & 1.3627 & 0.0537 \\
\hline & Unused land & 0.2167 & 3.4748 & 0.1003 & 1.2956 & 0.1226 \\
\hline & Construction land & 0.1187 & 0.4905 & 0.4909 & 1.2890 & 0.1639 \\
\hline \multirow{6}{*}{2002} & Water area & 0.0675 & 0.7138 & 0.1699 & 1.4557 & 0.1416 \\
\hline & Cultivated land & 0.0016 & 0.0234 & 0.5925 & 1.3389 & 0.0763 \\
\hline & Forest & 0.0870 & 1.3303 & 0.0881 & 1.3439 & 0.1248 \\
\hline & Grass land & 0.0314 & 0.5082 & 0.0700 & 1.3109 & 0.0548 \\
\hline & Unused land & 0.3510 & 3.6075 & 0.1173 & 1.3019 & 0.1823 \\
\hline & Construction land & 0.1111 & 0.4132 & 0.5006 & 1.2557 & 0.1739 \\
\hline \multirow{6}{*}{2016} & Water area & 0.0617 & 0.6725 & 0.1645 & 1.4904 & 0.1628 \\
\hline & Cultivated land & 0.0022 & 0.0278 & 0.5672 & 1.3726 & 0.0749 \\
\hline & Forest & 0.0771 & 1.0628 & 0.0998 & 1.4266 & 0.1265 \\
\hline & Grassland & 0.0366 & 0.5762 & 0.0573 & 1.3236 & 0.0689 \\
\hline & Unused land & 0.3234 & 3.5279 & 0.1040 & 1.3187 & 0.1436 \\
\hline & Construction land & 0.1003 & 0.3515 & 0.5274 & 1.2745 & 0.1863 \\
\hline
\end{tabular}

disturbance on unused land was up to its highest in 2002. The changes of the water area landscape metrics also took on an obvious periodicity. The values of $C, S$ and Do declined after 2002, which suggested that the ecological risk affecting the water area was similar to the unused land suffered. The decrease of PAFRAC and the increase of $N$ reflected the decline of the stability of the water area patch.

During 1989 to 2016, the area of forest nearly doubled and the value of Do obviously increased. While the $C$ and $S$ of the forest initially increased and then gradually decreased. These changes meant that the forest expanded mainly in a scattered way during 1989 to 2002 , but then in a relative aggregation way. The $C$ and $S$ of grassland remained relatively low, but significantly increased from 1989 to 2016. Due to urbanization and quarrying, the area of grassland was smaller with a lower Do. The changes of PAFRAC and $N$ mean that the patch of grassland became increasingly unstable.

According to the results of landscape metrics, the landscape disturbance indices of each land use type in different years were calculated. Then the ERI model was established to calculate the value of each risk unit. With the help of the natural breakpoint method in Arc GIS 10.2, the result of the ERI were divided into five grades: extremely high, high, medium, low and extremely low [15]. The assessment results showed that the average ERI values in 1989, 2002 and 2016 were as follows: $0.0438,0.052$ and 0.0501 , which illustrated that the landscape ecological risk in 2002 was the highest and then declined slightly.

\section{The Distribution and Changes of Landscape Ecological Risk}

The semi-variance function was conducted to obtain the result of spatial interpolation for the ERI. Spatial fitting is the key step of the semi-variance function, the result shows that the exponential model best satisfied for the experimental semivariance function of 1989 and 2016, the spherical model best satisfied for that of 2002 by comparing the results of $R^{2}$ and $R S S$. Based on the results of the spatial fitting, the ordinary kriging interpolation method was adopted to generate the spatial interpolation maps of landscape ecological risk for each study year, as shown in Fig. 5.

The results of Fig. 5 show that the landscape ecological risk pattern in 1989 was similar to that in 2002. The extremely low-risk regions were mostly distributed in the hilly areas of Huaibei. In 1989 and 2002, the extremely high and high-risk regions were concentrated in northern Huaibei, which was more affected by human activities. These areas had the longest history of mining and the number of coal mines was the largest. From the overlaying analysis of the spatial interpolation maps for the ERI and the minefield map, it can be found that $81.14 \%$ of the extremely high-risk regions and $58.97 \%$ of the high-risk regions 

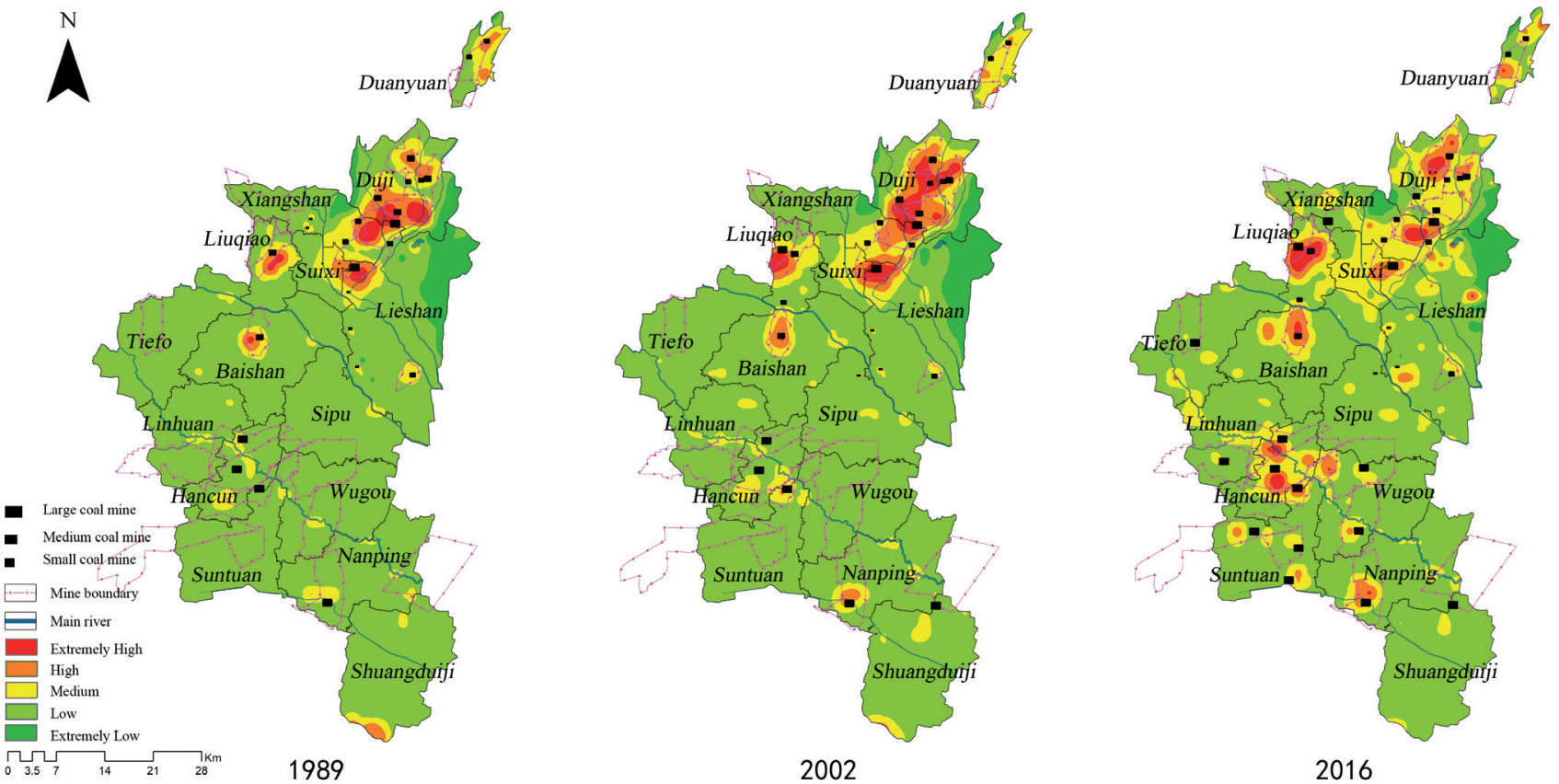

Fig. 5. Spatial interpolation maps for the ERI in Huaibei from 1989 to 2016.

distributed in the mining areas in 1989. The proportions in 2002 were $90.15 \%$ and $75.5 \%$, which illustrated that mining was the main factor that affected the distribution of the extremely high and high-risk regions in Huaibei. As Fig. 5 shows, the expansion of the medium and high-risk regions were closely related to construction land.

The distribution gradient of the landscape ecological risk in 2016 was different from that in 1989 and 2002, which mainly signifies that the expansion of the extremely high and high-risk regions was characterized by continuity during 1989 to 2002. Since 2002, the regions have expanded in a scattered way, which is mainly because most coal mines located in northern Huaibei have since closed. Due to the ecological restoration in the mining areas, the area of extremely high-risk regions in northern Huaibei obviously decreased. However, the impact of mining subsidence on the landscape ecological risk pattern still cannot be ignored. In 2016, 92.23\% of the extremely highrisk regions and $71.16 \%$ of the high-risk regions were distributed in the mining areas. It should be noted that the ecological risk grade of mid-Huaibei will rise further as a result of the development of the mining industry.

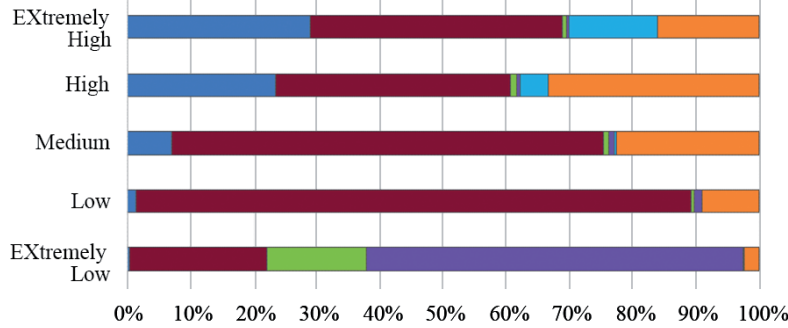

a)

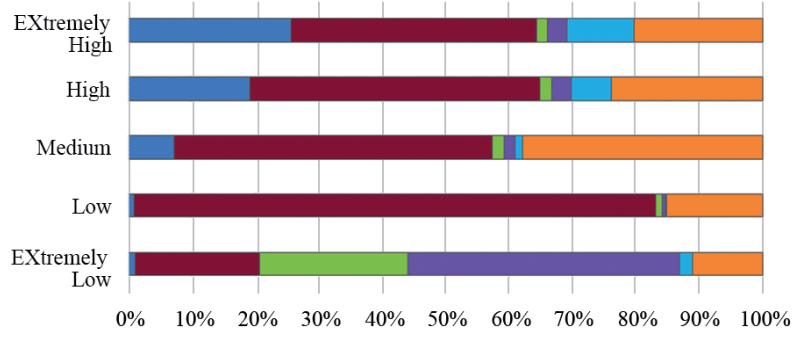

c)

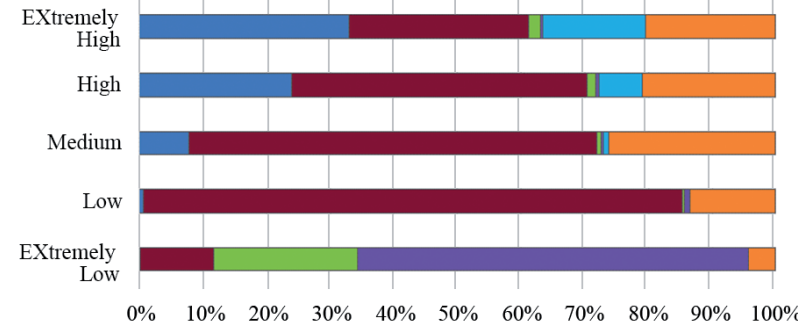

b)

Fig. 6. Land use composition in various risk regions in 1989 a), 2002 b), 2016 c). 
Table 6. The changes of landscape ecological risk in Huaibei from 1989 to $2016\left(\mathrm{~km}^{2}\right)$.

\begin{tabular}{|c|c|c|c|c|c|}
\hline Year & Extremely Low & Low & Medium & High & Extremely High \\
\hline 1989 & 102.54 & 2310.73 & 207.96 & 87.12 & 33.25 \\
\hline 2002 & 107.84 & 2233.60 & 241.57 & 102.70 & 55.89 \\
\hline 2016 & 76.51 & 1963.57 & 542.16 & 124.63 & 34.73 \\
\hline
\end{tabular}

In northern Huaibei, the medium-risk regions sprawled towards the southeast and east, which was consistent with construction land.

Meanwhile, in mid-Huaibei, the medium-risk regions increased around the new mines and along the Kuaihe River, which was surrounded by a number of villages. By using the overlaying analysis tools of Arc GIS 10.2, we summarized the land use composition of the ecological risk regions in different grades (Fig. 6). The largest land use types in the extremely low-risk regions were grassland, forest and cultivated land, the mean ratios of these land use types across the three years were $54.54 \%, 20.64 \%$ and $17.62 \%$. The low-risk regions were largely covered by cultivated land, which accounted for more than $80 \%$ in all of the years. The medium-risk regions largely consisted of construction land and cultivated land, the mean ratios of these land use types across the three years were $60.88 \%$ and $28.89 \%$. In the high-risk regions, the proportions of cultivated land, construction land and water area were high, and the mean ratios of these land use types across the three years were $43.07 \%, 26.08 \%$, and $22.18 \%$. From 1989 to 2016, the land use composition of the extremely high-risk regions was relatively complex. The water area, cultivated land, unused land and construction land were the important components, and the mean ratios of these land use types across the three years were $35.57 \%, 29.22 \%, 18.94 \%$ and $13.65 \%$, respectively.

\section{Landscape Ecological Risk Conversion Analysis}

Table 6 shows the statistical results of different ecological risk grades in each year. In the observed 27 years, the area of the extremely high- and the extremely low-risk regions initially increased and decreased afterward. Both the high- and medium- risk regions increased constantly. However, the area of low-risk regions decreased constantly. From 1989 to 2016, the area of low-risk regions decreased by $347.16 \mathrm{~km}^{2}$ with a reduction rate of $15.02 \%$, which was the largest change. The medium- and high-risk regions increased by $334.19 \mathrm{~km}^{2}$ and $37.51 \mathrm{~km}^{2}$, with growth rates of $160.7 \%$ and $43.05 \%$, respectively. The extremely high-risk regions increased by $22.64 \mathrm{~km}^{2}$ during 1989 to 2002 and then decreased by $21.16 \mathrm{~km}^{2}$ during 2002 to 2016. Eventually, it increased by $4.46 \%$ compared with that in 1989. The extremely low-risk regions, which increased by $5.3 \mathrm{~km}^{2}$, were relatively stable in the first phase, whereas they rapidly decreased by $31.33 \mathrm{~km}^{2}$ during 2002 to 2016 . Finally, the extremely low-risk regions decreased by $25.38 \%$ compared with 1989.

Table 7 describes the conversions among different ecological risk grades from 1989 to 2002. Due to urbanization, the transition area from low risk grade to medium risk grade was $109.25 \mathrm{~km}^{2}$, with an annual growth of $8.4 \mathrm{~km}^{2}$, which was the largest variable. The mining industry was still developing over 13 years. As new mines come online and large mines offer continuous mining, the disturbance intensity of human activities obviously strengthens. As the results show, the extremely high-risk regions spread rapidly. By 2002, $36.36 \mathrm{~km}^{2}$ of medium-risk regions were converted into high-risk regions, and $21.16 \mathrm{~km}^{2}$ of high risk-regions changed into extremely high-risk regions. Other significant changes include the conversion of $54.62 \mathrm{~km}^{2}$ of the medium-risk regions into low-risk regions, and the conversion of 25.38 $\mathrm{km}^{2}$ of the high-risk regions into medium-risk regions. The changing areas are mostly distributed in the old and small mining areas. In this phase, some abandoned mine land and waterlogged subsidence basins were reclaimed to farmland and plantations. In addition, the closure of small coal mines has also lowered the local ecological risk grade. Overall, the total area of extremely low and

Table 7. Ecological risk transition matrix of Huaibei from 1989 to $2002\left(\mathrm{~km}^{2}\right)$.

\begin{tabular}{|c|c|c|c|c|c|}
\hline 1989 to 2002 & Extremely Low & Low & Medium & High & Extremely High \\
\hline Extremely Low & 95.92 & 6.62 & 0 & 0 & 0 \\
\hline Low & 11.92 & 2170.21 & 109.25 & 11.33 & 8.03 \\
\hline Medium & 0 & 54.62 & 104.84 & 36.36 & 12.14 \\
\hline High & 0 & 2.14 & 25.38 & 38.45 & 21.16 \\
\hline Extremely High & 0 & 0.02 & 2.11 & 16.56 & 14.56 \\
\hline
\end{tabular}


Table 8. Ecological risk transition matrix of Huaibei from 2002 to $2016\left(\mathrm{~km}^{2}\right)$.

\begin{tabular}{|c|c|c|c|c|c|}
\hline 2002 to 2016 & Extremely Low & Low & Medium & High & Extremely High \\
\hline Extremely Low & 70.46 & 29.81 & 5.54 & 1.79 & 0.23 \\
\hline Low & 6.05 & 1867 & 321.78 & 34.11 & 4.68 \\
\hline Medium & 0 & 54.97 & 143.04 & 36.42 & 7.13 \\
\hline High & 0 & 6.52 & 48.86 & 33.60 & 13.71 \\
\hline Extremely High & 0.02 & 5.29 & 22.90 & 18.71 & 8.97 \\
\hline
\end{tabular}

low-risk regions slightly increased by 3\% during 1989 to 2002. Meanwhile, the total area of extremely high and high-risk regions increased by $31.75 \%$. The medium-risk regions increased by $16.16 \%$. Consequently, the risk grade of Huaibei presents an uptrend over 13 years.

The results in Table 8 show that during 2002 to 2016, $321.78 \mathrm{~km}^{2}$ of low-risk regions changed into medium-risk regions with an annual growth of $8.4 \mathrm{~km}^{2}$, which was faster than the growth during 1989 to 2002. Compared with the land ecological risk distribution maps in 2002 and 2016, the changing areas were mostly located in the north and middle of Huaibei. In the northern area, urbanization was the important driving force for the increase of the medium-risk regions. In the middle area, the increase of the medium-risk region was mainly because of the construction of new mines and the expansion of surrounding towns. Other obvious risk upgrades included the conversion of 34.11 $\mathrm{km}^{2}$ of low-risk regions and $36.42 \mathrm{~km}^{2}$ of medium-risk regions into high-risk regions, which was largely due to the expansion of subsidence basin. The exploitation of hilly areas in the east area destroyed some forest and grassland, which caused the conversion of $29.81 \mathrm{~km}^{2}$ of extremely low-risk regions into low-risk regions. The obvious risk of downgrading includes the conversion of $54.97 \mathrm{~km}^{2}$ of medium-risk regions into low-risk regions. Meanwhile, $48.86 \mathrm{~km}^{2}$ of high-risk regions and 22.90 $\mathrm{km}^{2}$ of extremely high-risk regions degraded to mediumrisk regions mainly because of ecological restoration in the mining areas. Overall, the total area of extremely low and low-risk regions decreased by $12.98 \%$, while the medium-risk regions increased by $124.43 \%$ from 2002 to 2016. The total area of extremely high and highrisk regions was relatively stable, which just increased by $0.49 \%$. Consequently, although the higher-grade risk regions were controlled effectively, the medium-risk regions increased rapidly.

\section{Spatial Autocorrelation of Ecological Risk Index}

The global spatial autocorrelation for landscape ecological risk is closely related to spatial gain. Fig. 7 shows the calculation results of Moran's I at different distance classes within the range of 1.5 to $20 \mathrm{~km}$. It is clear that all Moran's I values were greater than 0 , which implied that the spatial autocorrelation of the ERI was positive. Moran's I at the distance class of $1.5 \mathrm{~km}$ was the largest and declined with the increase of spatial distance. This indicated the higher spatial distance and lower spatial autocorrelation. When the spatial distance was beyond $15 \mathrm{~km}$ the spatial pattern of the ERI approached random distribution in 1989 and 2002, and it was $10 \mathrm{~km}$ in 2016. Moran's I increased at the same gain level from 1989 to 2002 but significantly declined in 2016, which implied that the spatial autocorrelation of the ERI was the highest in the mature period, and lowest in the recession period. As shown in Fig. 5, the extremely low, extremely high and high-risk regions were continuously distributed with a few patches in 2002. However, these regions were fragmented into small pieces in 2016.

Fig. 8 shows the results of local spatial autocorrelation for the ERI. The spatial distribution of H-H and L-L clusters in 1989 were similar to that in 2002. In these two years, the $\mathrm{H}-\mathrm{H}$ clusters concentrated in northern Huaibei and the area in 2002 was larger. In that area, the central city was built up beside mining areas, which resulted in the main risk sources, urbanization and mining being closely adjacent. Therefore, the ecological environment of the northern region was exposed to a higher ecological risk. L-L clusters were mostly located in the east and north of central city where they were occupied by grassland and forest, implying that the probability of ecological risk rising was low. In 2016, the spatial distribution patterns of $\mathrm{H}-\mathrm{H}$ clusters obviously changed. The $\mathrm{H}-\mathrm{H}$ clusters in the north were

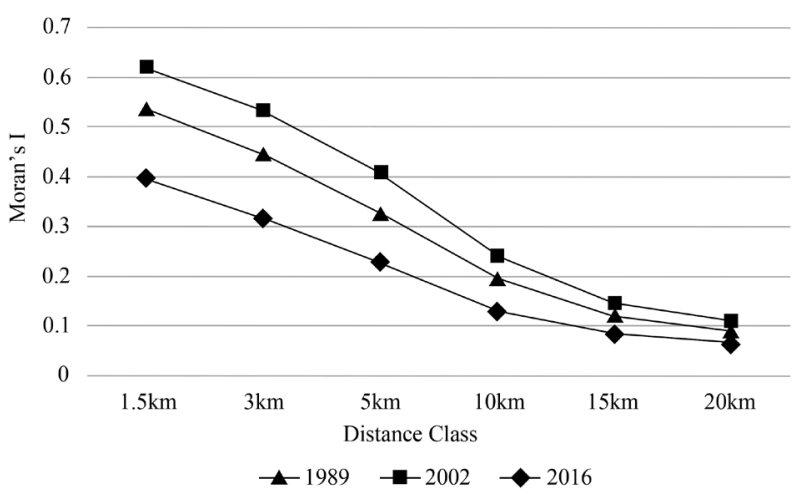

Fig. 7. Moran's I value for the ERI under different granularities. 

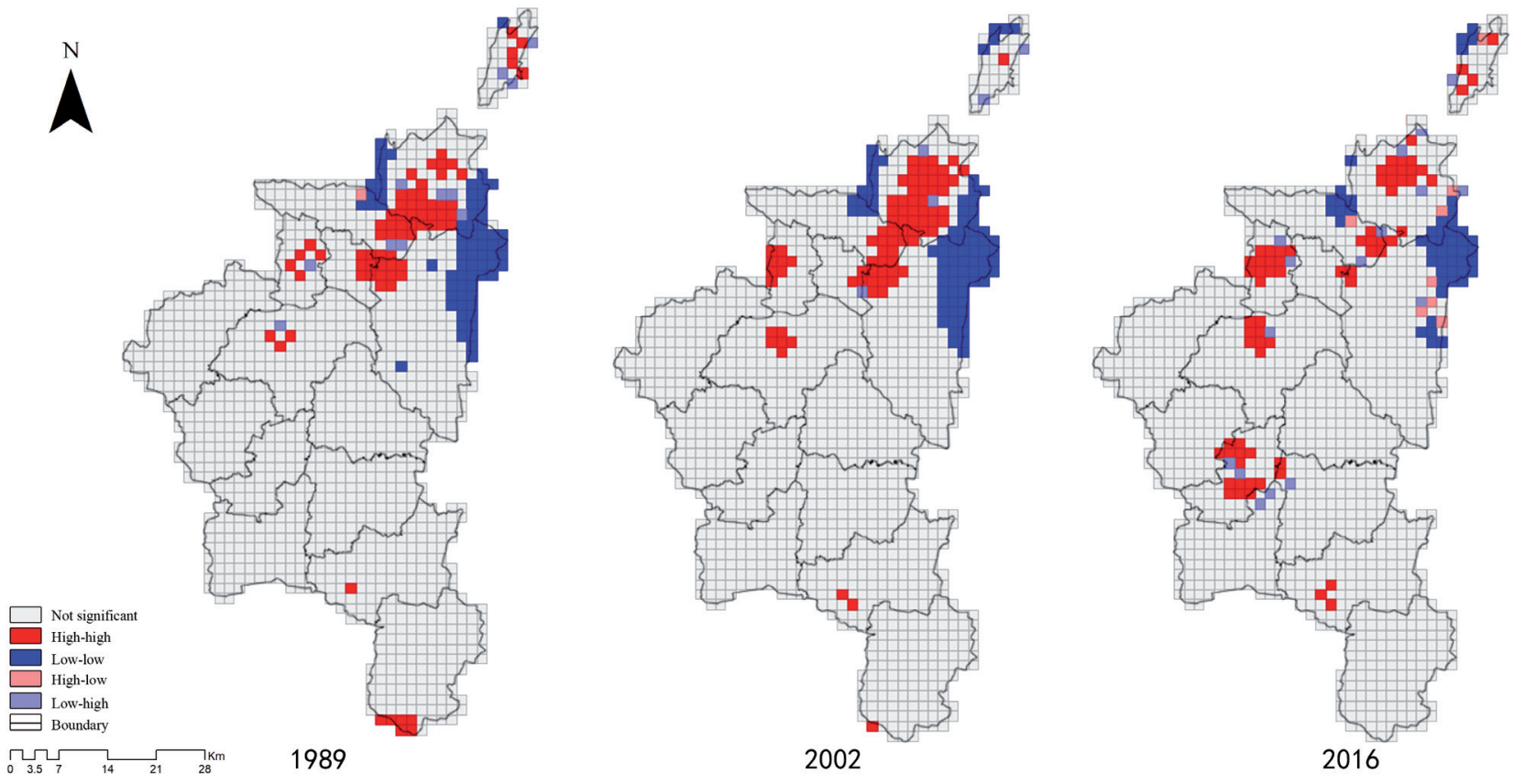

Fig. 8. Spatial cluster maps using local spatial autocorrelation for ERI in Huaibei from 1989 to 2016.

divided into small pieces, indicating that the distribution of H-H clusters became scattered in 2016. This signified that the ecological environment in the northern region had been effectively improved, since the mining activity declined. In the middle of Huaibei, the formation of new $\mathrm{H}-\mathrm{H}$ clusters indicated that the probability of ecological risk was rising. In addition, the L-H clusters increased around the $\mathrm{H}-\mathrm{H}$ clusters, which indicated that the level of ecological risk was very unstable in the periphery of mining areas.

\section{Discussion}

Mining activity is a serious means of human disturbance [42]. Both opencast mining and underground mining will inevitably result in significant changes in the land use structures. The ecological security of resourcebased cities is directly threatened by land use changes [43]. Moreover, the mining industry has promoted the development of cities, which has indirectly affects the landscape pattern on a larger scale. LERA provides a holistic view for understanding the effects of the mining industry on regional landscape patterns. As a typical resource-based city, Huaibei has experienced a rapid development period, a mature period and a recession period since the 1980s. The evolution of land use and landscape ecological risk is representative.

Urbanization was the primary driving force of land use changes throughout the whole study period. As a result, construction land was the fastest-growing land use type. The land use transition matrices showed that a total of $229.54 \mathrm{~km}^{2}$ of cultivated land has been converted into construction land, which was the main source of the increase of construction land during 1989 to 2016. Influenced by economic factors and government policies, especially for urban planning, the construction land sprawled along the railway lines to the northeast, southwest and southeast. Residential, administration and public service land and urban green space played a role in filling and linking. In recent years, with the recession of the mining industry, industrial abandoned land has sharply increased. The future of urban planning should aim at smart growth, which includes controlling the growth of construction land and paying more attention to the renewal of industrial abandoned land and the old community. LERA results showed that the increase of construction land had an obvious impact on the medium-risk regions. Therefore, the medium-risk regions constantly increased over the 27-year period. By 2016, the area of medium-risk regions was 3.4 times larger than the total area of extremely high and high-risk regions. Due to the recession of the mining industry, controlling the ecological risk caused by urbanization will become the focus of ecological restoration in the future. Therefore, Huaibei should take action to limit the growth of construction land and to optimize the distribution of cities and towns.

Compared with urbanization, the disturbance of mining on the landscape pattern is more complicated. During the rapid development period, a large amount of cultivated land, rural residential areas and plantations changed into industrial land, abandoned mine land and waterlogged subsidence basins, which led to higher fragmentation in the mining areas. From the results of the LERA, it could be found that mining activity was an important reason for the formation of the extremely high-risk regions and obviously affected the highrisk regions. It was not until many coal mines closed that the extremely high and high-risk regions began 
to decrease. In the process, land reclamation planning and ecological restoration planning played an important role. A total of $90.67 \mathrm{~km}^{2}$ of abandoned mine land and waterlogged subsidence basins were reclaimed by the end of 2015. However, the reclamation rate was just $42.11 \%$. The reasons for the low reclamation rate in Huaibei are multifarious. Firstly, the amount of abandoned mine land formed decades ago and many coal mines have been closed, so it was hard to confirm the subject of responsibility. There are still large gaps between decision-making and planning implementation. Secondly, the scientific basis for ecological restoration planning is insufficient. Ecological restoration planning has rarely referenced the results of landscape ecological assessment on a regional scale. Some studies have indicated that the grade of landscape ecological risk in the local area did not decline after land reclamation. Therefore, it is necessary to improve the ecological restoration planning method and the planning mechanism.

From 1989 to 2002, the mining industry was the most important economic activity in Huaibei, with a large employed population that affected economic and social development. The spatial distribution of construction land must adapt to the development of the mining industry, which means that spatial correlation between the two main risk sources was strong. In the periods when the mining industry was developed, the disturbance of urbanization on land use was also very significant. With the change of the industry structure, the correlation gradually declined. At the local scale, the distribution of H-H clusters and L-L clusters in 1989 and 2002 was different from that in 2016. According to the spatial cluster maps for the ERI, the H-H clusters that were located in Lieshan, Xiangshan and Duji were reduced from 2002 to 2016, which illustrates that the probability of risk rising in these regions was declining. However, in Liuqiao, Baishan and Hancun, the $\mathrm{H}-\mathrm{H}$ clusters increased rapidly, which indicates the ecological risk spread in these areas. Therefore, these regions should be regarded as the critical zones of ecological risk prevention. During 2002 to 2016, the L-L clusters in Lieshan obviously shrank. Hence, Huaibei should take action to limit the intensity of development in hills and in surrounding buffer zones.

There have been some important discoveries about the phase characteristics of land use and the landscape ecological risk in resource-based cities, while there are also some limitations. The assessment method used in this study can show the impact of land use changes on the entire ecosystem. The results are more effective for regional planning. However, it is usually difficult to accurately reflect the ecological effect of a specific risk source. This study referenced detailed mining data and urban planning maps in different years. With the help of geographic information system (GIS), we partially identified the change process and influences of urbanization and mining activity. However, further analysis is still needed to reflect the disturbance process of a certain risk source to a single receptor in detail.

\section{Conclusion}

In this study, we analysed the spatiotemporal evolution of land use and landscape ecological risk in a resource-based city. The main conclusions are as follows: Firstly, from 1989 to 2016, the primary driving force of land use changes was urbanization, especially in the occupation of cultivated land. Mining activity resulted in the conversion of cultivated land into subsidence basins and abandoned mine lands. At the same time, many rural residential areas were damaged. Secondly, during the study period, the average landscape ecological risk first increased and then decreased. There was an obvious correlation between mining activity and the distribution of extremely high and high-risk regions. Meanwhile, the expansion of the medium-risk regions was significantly influenced by urbanization. Finally, the global spatial autocorrelation of the landscape ecological risk was higher during the rapid development period and the mature period, but obviously declined during the recession period. The results of LISA show that the pattern of $\mathrm{H}-\mathrm{H}$ clusters and $\mathrm{L}-\mathrm{L}$ clusters was quite different before and after the recession period.

These findings could provide some suggestions for land use planning and the ecological risk management of resource-based cities. During the rapid development period, a large amount of abandoned mine lands were generated. If these abandoned mine lands are not reclaimed in time, the extremely high and high-risk regions will continuously increase. Unfortunately, this problem is widespread in the resource-based cities of China [21]. For the resource-based cities in the rapid development period, the emphasis of ecological risk management is to improve the monitoring and assessment mechanism and to establish a hierarchical risk management strategy. On the basis of scientific ecological restoration planning for mining areas, a sustainable mode of simultaneous mining and ecological restoration should be adopted to avoid the continuous increase of the abandoned mine land. In resource-based cities, the recession period is also a transition period for the economy and society, in which economic structure will become more pluralistic. The development of emerging industries will lead to the renewed growth of construction land and the loss of cultivated land, which will upgrade the ecological risk of the local area and cause new problems for sustainable development. Hence, the land use management policy should encourage the development of emerging industries by using abandoned mine land and protecting cultivated land from urbanization during the recession period in order to reduce the ecological risk probability.

\section{Acknowledgements}

This study was supported by the National Natural Science Foundation of China (No. 41671524), the 
Natural Science Foundation of Jiangsu Province of China (BK20170272) and the Fundamental Research Funds for the Central Universities (2017QNA28).

\section{Conflict of Interest}

The authors declare no conflict of interest.

\section{References}

1. LANDIS W.G. Ecological risk assessment conceptual model formulation for nonindigenous species. Risk Analysis, 24 (4), 847, 2004.

2. NEUBERT M., NAUMANN T., HENNERSDORF J., NIKOLOWSKI J. The geographic information systembased flood damage simulation model HOWAD. Journal of Flood Risk Management, 9 (1), 36, 2016.

3. GONG J., YANG J., TANG W. Spatially explicit landscape-level ecological risks induced by land use and land cover change in a national ecologically representative region in China. International Journal of Environmental Research and Public Health, 12 (11), 14192, 2015.

4. LI J., PU R., GONG H., LUO X., YE M., FENG B. Evolution characteristics of landscape ecological risk patterns in coastal zones in Zhejiang Province, China. Sustainability, 9 (4), 584, 2017.

5. SUTER G.W. Endpoints for regional ecological risk assessments, Environmental Management, 14 (1), 9, 1990.

6. BAYLISS P., VAN DAM R.A., BARTOLO R.E. Quantitative ecological risk assessment of the Magela Creek Floodplain in Kakadu National Park, Australia: comparing point source risks from the ranger uranium mine to diffuse landscape-scale risks. Human and Ecological Risk Assessment, 18 (1), 115, 2012.

7. PENG J., ZONG M., HU Y., LIU Y., WU J. Assessing landscape ecological risk in a mining city: a case study in Liaoyuan city, China. Sustainability, 7 (7), 8312, 2015.

8. JAVED T., AHMAD N., MASHIATULLAH A. Heavy metals contamination and ecological risk assessment in surface sediments of namal lake, Pakistan. Polish Journal of Environmental Studies, 27 (2), 675, 2018.

9. HOPE B.K. An examination of ecological risk assessment and management practices. Environment International, 32 (8), 983, 2006.

10. LANDIS W.G., WIEGERS J.K. Ten years of the relative risk model and regional scale ecological risk assessment. Human and Ecological Risk Assessment, 13 (1), 25, 2007.

11. AYRE K.K., LANDIS W.G. A Bayesian approach to landscape ecological risk assessment applied to the Upper Grande Ronde Watershed, Oregon, 18 (5), 946, 2012.

12. FAN J., WANG Y., ZHOU Z., YOU N., MENG J. Dynamic ecological risk assessment and management of land use in the middle reaches of the Heihe river based on landscape patterns and spatial statistics. Sustainability, 8 (6), 536, 2016.

13. SHI H., YANG Z., HAN F., SHI T., LI D. Assessing landscape ecological risk for a world natural heritage site: a case study of Bayanbulak in China. Polish Journal of Environmental Studies, 24 (1), 269, 2015.

14. ZHOU D., SHI P., WU X., MA J., YU J. Effects of urbanization expansion on landscape pattern and region ecological risk in Chinese coastal city: a case study of
Yantai city. The Scientific World Journal, 10, 1, 2014.

15. MO W., WANG Y., ZHANG Y., ZHUANG D. Impacts of road network expansion on landscape ecological risk in a megacity, China: a case study of Beijing. Science of the Total Environment, 574, 1000, 2017.

16. NIXDORF B., LESSMANN D., DENEKE R. Mining lakes in a disturbed landscape: application of the EC water framework directive and future management strategies. Ecological Engineering, 24 (12), 67, 2005.

17. KANWAR P., BOWDEN W.B., GREENHALGH S. A regional ecological risk assessment of the Kaipara Harbour, New Zealand, Using a Relative Risk Model, 21 (4), 1123, 2015.

18. CUI L., ZHAO Y., LIU J., HAN L., AO Y., YIN S. Landscape ecological risk assessment in Qinling Mountain. Geological Journal, 53, 342, 2018.

19. DAI W., DONG J., YAN W., XU J. Study on each phase characteristics of the whole coal life cycle and their ecological risk assessment - a case of coal in China. Environmental Science and Pollution Research, 24 (2), 1296, 2017.

20. ZHANG W.Z., YU J.H., WANG D., KAN L. Classification and development orientation of resource-based cities. Study on Sustainable Development of Resource-based Cities in China; Niu L., Science Press: Beijing, P. R. China Volume 1, 140, 2014.

21. GUO K., KUAI X., CHEN Y., QI L., ZHANG L., LIU Y. Risk assessment of land ecology on a regional scale: application of the relative risk model to the mining city of Daye, China. Human and Ecological Risk Assessment, 23 (3), 550, 2017.

22. PANDEY B., AGRAWAL M., SINGH S. Ecological risk assessment of soil contamination by trace elements around coal mining area. Journal of Soils and Sediments, 16 (1), 159, 2016.

23. PENG J., ZONG M., HU Y., LIU Y., WU J. Assessing landscape ecological risk in a mining city: a case study in Liaoyuan City, China. Sustainability, 7 (7), 8312, 2015.

24. YUCEL M.A., TURAN R.Y. Areal Change Detection and 3D Modeling of mine lakes using high-resolution unmanned aerial vehicle images. Arabian Journal for Science and Engineering, 41 (12), 4867, 2016.

25. DEAL B., SCHUNK D. Spatial dynamic modeling and urban land use transformation: a simulation approach to assessing the costs of urban sprawl. Ecological Economics, 51 (12), 79, 2004.

26. LIN Y., HU X., ZHENG X., HOU X., ZHANG Z., ZHOU X., QIU R., LIN J. Spatial variations in the relationships between road network and landscape ecological risks in the highest forest coverage region of China. Ecological Indicators, 96, 392, 2019.

27. ZURQANI H.A., POST C.J., MIKHAILOVA E.A., SCHLAUTMAN M.A., SHARP J.L. Geospatial analysis of land use change in the Savannah river basin using Google Earth Engine. International Journal of Applied Earth Observation and Geoinformation, 69, 175, 2018.

28. LI Y., HUANG S. Landscape ecological risk responses to land use change in the Luanhe river basin, China. Sustainability, 7 (12), 16631, 2015.

29. AREENDRAN, G., RAO P., RAJ K., MAZUMDAR S., PURI K. Land use/land cover change dynamics analysis in mining areas of Singrauli district in Madhya Pradesh, India. Tropical Ecology, 54 (2), 239, 2013.

30. DEZHKAM S., JABBARIAN A.B., DARVISHSEFAT A.A., SAKIEH Y. Performance evaluation of land change simulation models using landscape metrics. Geocarto 
International, 32 (6), 623, 2017.

31. PAN J., LIU X. Landscape Ecological Risk Assessment and Landscape Security Pattern Optimization in Shule River Basin. Chinese Journal of Ecology, 35 (3), 791, 2016.

32. REN Z.Y., ZHANG H. Effects of land use change on landscape pattern vulnerability in Yinchuan Basin, Northwest China. Chinese Journal of Applied Ecology, 27 (1), 243, 2016.

33. SUN C., YAN X., ZHONG J. Evaluation of the Landscape Patterns Vulnerability and Analysis of Spatial Correlation Patterns in the Lower Reaches of Liaohe River Plain. Acta Ecologica Sinica, 34 (2), 247, 2014.

34. PATHAK S., OJHA C., ZEVENBERGEN C., GARG R. Ranking of Storm Water Harvesting Sites Using Heuristic and Non-Heuristic Weighing Approaches. Water, 9 (9), 710, 2017.

35. LI Y., HUANG S. Landscape Ecological Risk Responses to Land Use Change in the Luanhe River Basin, China. Sustainability, 7 (12), 16631, 2015.

36. DOLEŽALOVÁ J., VOJAR J., SMOLOVÁ D., SOLSKÝ M., KOPECKÝ O. Technical reclamation and spontaneous succession produce different water habitats: A case study from Czech post-mining sites. Ecological Engineering, 43, $5,2012$.

37. XIAO L., TIAN G. Eco-risk Assessment of Land Use in Tianjin City. Chinese Journal of Ecology, 33 (2), 469,
2014.

38. ANSELIN L., GETIS A. Spatial statistical analysis and geographic information systems. Annals of Regional Science, 26 (1), 19, 1992.

39. HU X., XU H. A new remote sensing index for assessing the spatial heterogeneity in urban ecological quality: a case from Fuzhou city, China. Ecological Indicators, 89, 11, 2018.

40. DINIZ-FILHO J.A.F., BARBOSA A.C.O.F, COLLEVATTI R.G., CHAVES L.J., TERRIBILE L.C., LIMA-RIBEIRO M.S., TELLES M.P.C. Spatial autocorrelation analysis and ecological niche modelling allows inference of range dynamics driving the population genetic structure of a Neotropical savanna tree. Journal of Biogeography, 43 (1), 167, 2016.

41. ZANK B., BAGSTAD K.J., VOIGT B., VILLA F. Modeling the effects of urban expansion on natural capital stocks and ecosystem service flows: a case study in the Puget Sound, Washington, USA. Landscape and Urban Planning, 149, 31, 2016.

42. SONTER L.J., MORAN C.J., BARRETT D.J., SOARESFILHO B.S. Processes of land use change in mining regions. Journal of Cleaner Production, 84, 494, 2014.

43. MARTINUZZI S., GAVIER-PIZARRO G.I., LUGO A.E., RADELOFF V.C. Future land-use changes and the potential for novelty in ecosystems of the United States. Ecosystems, 18 (8), 1332, 2015. 